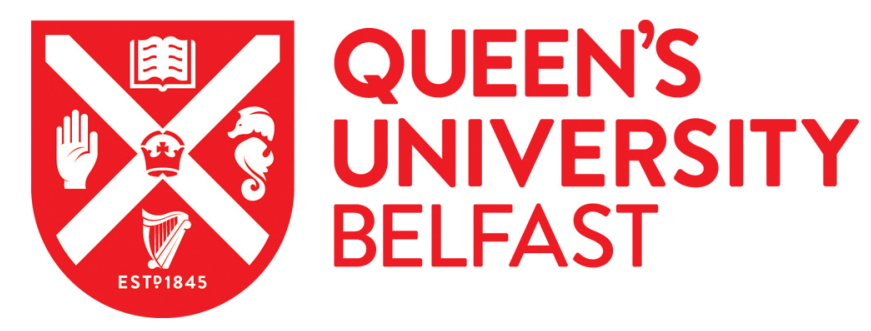

\title{
Effect of implementation of a preconception counselling resource for women with diabetes: A population based study
}

Holmes, V. A., Hamill, L. L., Alderdice, F. A., Spence, M., Harper, R., Patterson, C. C., Loughridge, S., McKenna, S., Gough, A., \& McCance, D. R. (2017). Effect of implementation of a preconception counselling resource for women with diabetes: A population based study. Primary Care Diabetes, 11(1), 37-45. https://doi.org/10.1016/j.pcd.2016.07.005

Published in:

Primary Care Diabetes

Document Version:

Peer reviewed version

Queen's University Belfast - Research Portal:

Link to publication record in Queen's University Belfast Research Portal

Publisher rights

(c) 2016 Elsevier Ltd. This manuscript version is made available under the CC-BY-NC-ND 4.0 license http://creativecommons.org/licenses/by$\mathrm{nc}-\mathrm{nd} / 4.0 /$ which permits distribution and reproduction for non-commercial purposes, provided the author and source are cited.

\section{General rights}

Copyright for the publications made accessible via the Queen's University Belfast Research Portal is retained by the author(s) and / or other copyright owners and it is a condition of accessing these publications that users recognise and abide by the legal requirements associated with these rights.

Take down policy

The Research Portal is Queen's institutional repository that provides access to Queen's research output. Every effort has been made to ensure that content in the Research Portal does not infringe any person's rights, or applicable UK laws. If you discover content in the Research Portal that you believe breaches copyright or violates any law, please contact openaccess@qub.ac.uk. 
Title: Effect of implementation of a preconception counselling resource for women with diabetes: a population based study.

Running title: impact of preconception counselling on pregnancy planning indicators

Authors: V.A. Holmes,${ }^{1}$ L.L. Hamill, ${ }^{1}$ F.A. Alderdice,${ }^{2}$ M. Spence, ${ }^{3}$ R. Harper ${ }^{4}$ C.C. Patterson, ${ }^{1}$ S. Loughridge,${ }^{5}$ S. McKenna, ${ }^{5}$ A. Gough, ${ }^{1}$ D.R. McCance,${ }^{5}$ for the Women with Diabetes Project Team*

${ }^{1}$ Centre for Public Health, School of Medicine, Dentistry and Biomedical Sciences, Queen's University Belfast, Belfast, UK; ${ }^{2}$ School of Nursing and Midwifery, Queen's University Belfast, Belfast, UK; ${ }^{3}$ School of Biological Sciences, Queen's University Belfast, Belfast, UK; ${ }^{4}$ Ulster Hospital, South Eastern Health and Social Care Trust, Dundonald, UK; ${ }^{5}$ Regional Centre for Endocrinology and Diabetes, Royal Victoria Hospital, Belfast, UK. * Members listed at end of paper

\section{Corresponding Author:}

Dr Valerie Holmes; Centre for Public Health, School of Medicine, Dentistry and Biomedical Sciences, Queen's University Belfast, Belfast BT12 6BA, UK. Phone: 028 90634245

Email:v.holmes@qub.ac.uk

Funding Source: Diabetes UK (grant number 07/0003548).

Conflicts of Interest: None of the authors have any potential conflicts of interest 


\section{ABSTRACT}

Aim To evaluate the effect of regional implementation of a preconception counselling resource into routine diabetes care on pregnancy planning indicators.

Methods A preconception counselling DVD was distributed to women by diabetes care teams and general practices. Subsequently, in a prospective population-based study, pregnancy planning indicators were evaluated. The post-DVD cohort $(n=135)$, including a viewed-DVD subgroup ( $n=58)$, were compared with an historical cohort (preDVD, $\mathrm{n}=114$ ). Primary outcome was $\mathrm{HbA1c}$ at first diabetes-antenatal visit. Secondary outcomes included preconception folic acid consumption, planned pregnancy and HbA1c recorded in the 6 months preconception.

Results Mean first visit HbA1c was lower post-DVD vs. pre-DVD: 7.5\% vs. $7.8 \%$ [58.4 vs. $61.8 \mathrm{mmol} / \mathrm{mol}$; $\mathrm{p}=0.12$ ), although not statistically significant. $53 \%$ and $20 \%$ of women with type 1 and 2 diabetes, respectively, viewed the DVD. The viewed-DVD subgroup were significantly more likely to have lower first visit HbA1c: $6.9 \%$ vs. $7.8 \%$ [52.1 vs. 61.8mmol/mol], $\mathrm{p}<0.001$; planned pregnancy (88\% vs. 59\%, $\mathrm{P}<0.001)$; taken folic acid preconception ( $81 \%$ vs. 43\%, $\mathrm{P}=0.001)$; and had $\mathrm{HbA1c}$ recorded preconception ( $88 \%$ vs. $53 \%, \mathrm{P}<0.001)$ than the pre-DVD cohort.

Conclusions Implementation of a preconception counselling resource was associated with improved pregnancy planning indicators. Women with type 2 diabetes are difficult to reach. Greater awareness within primary care of the importance of preconception counselling among this population is needed. 


\section{Highlights}

- Pregnancy planning and pre-pregnancy care uptake is poor among women with diabetes

- Poor preconception counselling is linked to poor pre-pregnancy care uptake

- Implementation of a preconception counselling resource improved pregnancy planning

- Women who engaged with the resource were better prepared for pregnancy

- Women with type 2 diabetes, typically cared for in primary care, are hard to reach 


\section{INTRODUCTION}

Women with diabetes preceding pregnancy are at significant risk of adverse pregnancy outcomes when compared to the general maternity population, with higher rates of miscarriage, congenital malformations and stillbirth [1-7]. Planning pregnancy with the emphasis on optimizing glycemic control before conception reduces the risk of adverse outcomes [6-10]. All women with diabetes of childbearing potential should be counselled as to the risks associated with pregnancy and diabetes and of the benefits of planning for pregnancy. This 'conversation' with women, referred to as preconception counselling, should be incorporated regularly into routine diabetes outpatient visits and primary care consultations from adolescence according to national guidelines $[11,12]$. However, preconception counselling rates among women with diabetes remain low $[13,14]$, with preconception counselling or contraception discussed with only $25 \%$ of women attending for annual review in one study [14].

In distinction from preconception counselling, pre-pregnancy care (PPC) is targeted specifically at women who are preparing for pregnancy [15]. While the emphasis of PPC is on glycemic control, other key components include prescription of high dose folic acid preconception and review of medications to ensure women avoid potentially teratogenic drugs. Despite the known benefits of PPC in reducing adverse outcomes, attendance remains suboptimal $[8,16]$; in one recent study only $27 \%$ of pregnant women attended formal PPC services [8]. While many women with diabetes are aware of the need to plan for pregnancy, they are often not aware of the reasons why $[17,18]$. To avoid unnecessary anxiety, women need to need to know why planning is important and must feel confident that they can effectively plan their pregnancies [18]. There is 
a clear need to deliver accessible and appropriate information in relation to pregnancy planning.

To address low preconception counselling rates among women with diabetes and the consequences associated with lack of pregnancy planning knowledge, the Women with Diabetes Project team developed an educational preconception counselling DVD $[17,19]$, which was evaluated among 97 women with diabetes for effectiveness in changing knowledge and attitudes towards preconception care. e study. Findings demonstrated effectiveness in increasing knowledge and enhancing attitudes of women with diabetes to preconception care [20], suggested that the DVD was an appropriate educational tool for use as a pre-pregnancy counselling resource to prepare women with diabetes for pregnancy. Since 2010, the DVD has been adopted throughout Northern Ireland as a preconception counselling resource. The aim of the current study was to evaluate the effect of implementation of the resource into routine care on indicators of pregnancy planning in women with diabetes. Furthermore, given that the prior evaluation showed that the resource significantly improved attitudes of women toward PPC, we hypothesised that women who both received and viewed the DVD would be more likely to plan for pregnancy resulting in significantly improved pregnancy planning indicators compared with women who conceived prior to implementation of the pre-pregnancy counselling resource. 


\section{METHODS}

This study is a prospective nationwide population based study across all five regional diabetes-antenatal clinics in Northern Ireland comparing pregnancy planning indicators in pre- and post-preconception counselling resource cohorts. Study participants were women with pre-gestational diabetes who delivered/were expected to deliver between February 2012 and January 2013 (post-DVD cohort), including a viewed-DVD subgroup, compared with an historical cohort from the same five clinics (pre-DVD comparison cohort from between $1^{\text {st }}$ September 2009 and $31^{\text {st }}$ August 2010)

(Figure 1). The intervention was a preconception counselling DVD distributed by diabetes care teams and general practices to women with diabetes of child bearing potential. This study was designed as a service evaluation utilising historic audit data as a comparison cohort and therefore did not require approval from a Research Ethics Committee. Local approvals were obtained.

\section{Intervention development and implementation}

A preconception counselling DVD resource was systematically developed using a combined user and multi-professional advisory group approach as described previously [19]. In brief, the content and style of the resource were guided by qualitative focus groups with women and by a multi-professional advisory group. The resource was underpinned by the Expanded Health Belief Model [21], is of 45-minutes duration and focuses on the importance of planning for pregnancy and on essential pregnancy planning advice in the form of a pre-pregnancy checklist. The DVD resource is women centred, featuring eight women with diabetes sharing their views and experiences, alongside an evidence-based commentary. The DVD has 3 parts: Part 1, "things you need to know", encompassing sections entitled 'contraception', 
'risks, 'why plan' and a 'pre-pregnancy checklist'; Part 2 "things you might not know" encompassing sections entitled 'support team', 'blood glucose targets, hypos and ketoacidosis' and 'diet'; and Part 3 "Things you may want to know!!" encompassing sections entitled ' $1{ }^{\text {st }} 2^{\text {nd }}$ and $3^{\text {rd }}$ trimester', 'Delivery' and 'Post-birth'.

Between October and December 2010, 6029 DVDs were distributed via healthcare professionals to all women with diabetes of childbearing age and potential within their care (Figure 1). All diabetes care teams within the five health and social care trusts in Northern Ireland (NI) adopted the resource as a preconception counselling resource. In addition, all general practices in NI were invited to request DVDs for distribution to patients under their care to ensure that women with type 2 diabetes, who did not attend secondary care, also received the resource. In total 34\% of general practices actively engaged with the distribution process, with the remaining practices sent a DVD for information and for use within their practice. Awareness of the DVD among women with diabetes was further enhanced by promotion of the resource at local meetings, a local press release and a Diabetes UK mail out which coincided with the DVD launch. Diabetes care teams and general practices distributed the DVDs as appropriate to the needs of their patients, with some mailing DVDs to all women of child-bearing potential and others choosing to give DVDs face to face in clinic. Prior to the implementation of the DVD resource into routine care, no other educational resources in relation to preconception counselling/care for women with diabetes were widely available in NI.

A period of at least 5 months was allowed to elapse between distribution of the DVD resource and anticipated first conception for inclusion in the service evaluation. This time period allowed women who received the DVD from their healthcare professional the opportunity to view the resource and to take the necessary steps to 
plan their pregnancies, including taking action to plan pregnancy (make lifestyle changes, attend PPC, commence folic acid and optimise blood glucose control).

\section{Study Population}

All women with diabetes preceding pregnancy (type 1 or type 2) who became pregnant after this period (first day of last menstrual period on or after 1st June 2011) and who attended one of the five joint diabetes-antenatal clinics in NI were eligible for inclusion. Data collection continued for 12 months.

Pregnancy planning indicators and maternal and neonatal outcomes were abstracted from patient notes by a midwife using a service evaluation tool, which replicated the audit tool used for the historical cohort. In addition the midwife inquired if the woman had received and viewed the DVD prior to conception, and the action they had taken as a consequence of watching the DVD.

Baseline comparison data were available from a regional audit of the same five regional joint diabetes-antenatal clinics across $\mathrm{NI}$, involving all deliveries/expected deliveries in women with pre-gestational diabetes between $1^{\text {st }}$ September 2009 and $31^{\text {st }}$ August 2010 (pre-implementation of the DVD; pre-DVD comparison cohort).

The primary outcome was $\mathrm{HbA1c}$ at first joint diabetes-antenatal clinic visit in women post implementation of the DVD (post-DVD cohort) compared with the pre-DVD cohort in an intention to treat analysis. Secondary outcomes comprised other indicators of pregnancy planning including: pre-pregnancy folic acid use, gestational age at first antenatal visit, record of $\mathrm{HbAlc}$ measured in 6 months prior to pregnancy and documented use of contraception prior to pregnancy. In addition pregnancy planning 
indicators were compared between women who both received and viewed the DVD (viewed-DVD) and those prior to the DVD launch (pre-DVD cohort). Maternal and neonatal outcomes included early pregnancy loss, congenital malformations and stillbirths. As women with type 1 and type 2 diabetes are at similar risk of poor pregnancy outcomes, and given the small numbers of women with type 2 diabetes in our population, analysis was carried out on all women with diabetes, type 1 and type 2 combined. Deprivation scores were obtained from the postcode of residence using the NI Multiple Deprivation Measure based on geographical area of residence to reflect socio-economic status [22]. Social deprivation scores were then divided into quintiles with women in the bottom quintile considered to be most socially deprived.

\section{Statistical analysis}

A sample size of 200 (100 in each of the pre- and post-DVD cohorts) was required to give an excess of $95 \%$ power to detect a $0.5 \%$ (or $5.5 \mathrm{mmol} / \mathrm{mol}$ ) difference in mean $\mathrm{HbA1c}$ between cohorts as statistically significant $(P<0.05$; two-tailed), assuming an inter-patient SD in HbA1c of $0.95 \%$ (or $10.4 \mathrm{mmol} / \mathrm{mol}$ ) as observed in a similar population [23]. Assuming that $45 \%$ of the comparison cohort took folic acid preconception [23], the study size had in excess of $80 \%$ power to detect a difference of $20 \%$ (e.g. an increase from $45 \%$ to $65 \%$ taking folic acid pre-conception) as statistically significant $(P<0.05$; two-tailed).

Comparisons between the comparison cohort (pre-DVD) and study cohort (post-DVD or viewed-DVD) were carried out using Chi-square or Fisher exact tests for categorical variables and two-tailed Student's $t$ test for continuous variables. Logistic regression 
(categorical variables) and multiple regression (continuous variables) were used to adjust these comparisons for diabetes type, diabetes duration, parity, social deprivation, age and booking hospital. Results were considered statistically significant at the $5 \%$ level.

\section{RESULTS}

\section{Maternal Characteristics}

In total, 135 women were included in the post DVD evaluation (post-DVD cohort), and 114 women from the baseline regional audit served as the comparison cohort (preDVD cohort). Characteristics of the women before and after the DVD launch are shown

in Table 1. Women pre and post DVD launch were similar in age, ethnicity, social deprivation, $\mathrm{BMI}$, diabetes duration and $1^{\text {st }}$ joint antenatal-metabolic clinic visit clinical measures, but there were significantly fewer nulliparous women in the post-DVD cohort.

\section{Pregnancy planning indicators}

Pregnancy planning indicators of women before and after DVD distribution, and of the subgroup of women who both received and viewed the DVD prior to their pregnancy are shown in Table 2. There was a non-significant reduction in mean $\mathrm{HbA} 1 \mathrm{c}$ at the $1^{\text {st }}$ joint antenatal-metabolic clinic post-DVD compared to pre-DVD. Post-DVD, women were significantly more likely to have had HbA1c recorded in the 6 months preconception and there were also indications of improved pregnancy planning; women were more likely to have reported that the pregnancy was planned and to have taken folic acid preconception. Post-DVD, women were less likely to have a record in 
their antenatal notes that they attended for or received pre-pregnancy counselling, however this was no longer significant when adjusted for confounding variables.

\section{Effectiveness of distribution programme}

While $62 \%$ of women reported receiving the DVD, $43 \%$ reported viewing the DVD prior to conception (viewed-DVD subgroup), with a larger proportion of women with type 1 diabetes receiving and viewing the DVD as outlined in figure 1.

Comparison of viewed-DVD subgroup to pre-implementation data

Characteristics of the viewed-DVD subgroup are shown in Table 1. Of those women who viewed the DVD, $22 \%$ were already attending for PPC, $36 \%$ proceeded to contact either their Diabetes Care Team or GP for PPC while 33\% made lifestyle changes based on the advice given in the DVD but did not seek professional advice. Only 9\% did not make changes or seek advice before pregnancy. The viewed-DVD subgroup had significantly lower $\mathrm{HbA} 1 \mathrm{c}$ at the $1^{\text {st }}$ antenatal-metabolic visit compared with the baseline comparator pre-DVD cohort as shown in Table 2. Compared with the preDVD cohort, the viewed-DVD subgroup were also significantly more likely to have planned their pregnancy $(P=0.001)$, to have taken folic acid preconception $(P<0.001)$, to have an $\mathrm{HbA} 1 \mathrm{c}$ recorded in the 6 months prior to pregnancy $(P<0.001)$, to have an $\mathrm{HbA} 1 \mathrm{c}$ below $7.0 \%$ or $53 \mathrm{mmol} / \mathrm{mol}(\mathrm{P}<0.05)$ at the first visit and to be a current nonsmoker $(P<0.05)$. A similar proportion of women who viewed the DVD had a record of receiving pre-pregnancy counselling in their antenatal records as in the pre-DVD period. 
Pregnancy progress and outcomes

Pregnancy progress and outcome indicators, before and after the DVD launch, including the subgroup of women who viewed the DVD prior to pregnancy are outlined in Table 3. Significant differences in glycemic control between the pre- and post-DVD cohorts were only evident in the $3^{\text {rd }}$ trimester, most likely as a reflection of improved diabetes care during pregnancy. However, improved glycemic control in the $1^{\text {st }}$ trimester was evident in the viewed-DVD subgroup compared with the pre-DVD cohort which may indicate improvement in pregnancy planning among those women who viewed the DVD.

Post-DVD significantly fewer women experienced fetal loss (miscarriage, termination of pregnancy or late fetal loss) compared to the pre-DVD cohort (14\% vs. 4.4\%), with the miscarriage/late fetal loss rate further reduced to $1.7 \%$ in the viewed-DVD subgroup. There were no stillbirths in the post-DVD cohort, compared with $3(2.6 \%)$ in the pre-DVD cohort. There was one neonatal death in the post-DVD cohort. There was no significant difference between any of the cohorts for any other indicators of pregnancy progress or for any other maternal or neonatal outcomes.

\section{DISCUSSION}

The current study evaluates the implementation of an innovative DVD preconception counselling resource for women with diabetes into routine healthcare in NI. While 
mean $\mathrm{HbA1c}$ at the first antenatal-metabolic visit was lower in the post-DVD cohort compared with the pre-DVD cohort, this did not reach statistical significance. However, women in the post-DVD cohort were significantly less likely to experience fetal loss which included miscarriage, termination of pregnancy and late fetal loss. For those women who viewed the DVD prior to conception, there was some evidence of enhanced pregnancy planning as indicated by improved glycemic control and folic acid uptake. Furthermore, the vast majority of women indicated that they made positive pregnancy planning decisions after viewing the resource, either by contacting a healthcare professional for PPC or actively making positive lifestyle changes.

While the impact of the resource on adverse pregnancy outcomes in this study is limited, demonstration of an effect was made difficult by the limited numbers of women and pragmatic nature of the study. In addition, our overall findings are in keeping with those of Willhoite and colleagues [24] who developed a programme to highlight the importance of preconception counselling to healthcare providers and women with diabetes in Maine, USA, in a region where only $34 \%$ of 185 pregnancies occurred in women who had received counselling. In addition, Pearson and colleagues [7] have previously reported on the benefits of planning pregnancy and formal pre-pregnancy care in relation to a similar composite adverse pregnancy outcome in women with type 1 diabetes. Tripahti and colleagues [25] also found improved first trimester glycemic control in women receiving preconception counselling. In the present study, HbA1c was non-significantly lower in the post-DVD cohort, however, this reduction reached significance in those who viewed the DVD. The positive impact of the implementation of the DVD into routine care on foetal loss is likely be a reflection of the comprehensive 
nature of pregnancy planning, and the fact that planning advice goes beyond glycemic control to include advice on folic acid supplementation, medications and lifestyle.

Prior to the DVD launch, we successfully evaluated the DVD among women with diabetes and reported the effectiveness of the DVD in increasing knowledge and enhancing attitudes of women with diabetes to PPC [20]. While similar findings of effectiveness have been reported for a preconception counselling resource aimed at adolescents in the US [26], the longer term impact on pregnancy planning in that cohort remains unknown as no pregnancies have yet been reported.

A particular strength of this study is the evaluation of the resource over a longer period using a population based approach, where the impact on pregnancy planning indicators in a subsequent pregnancy is explored. This study encompasses a large geographic region and captured maternal and neonatal outcomes for all women with diabetes delivering in the region, allowing an extensive evaluation of distribution and uptake of this resource.

However, our study has a number of limitations. It was not possible to determine which women also benefited from structured PPC, and antenatal records of pre-pregnancy counselling are likely to be a mixture of preconception counselling and structured PPC. In addition, the majority of women in this study were of white ethnicity, reflecting the background population of Northern Ireland, making the findings of this study generalizable to white populations. While data collection methodology was carefully repeated from pre to post audit it is well known that capture of early miscarriage in secondary care is difficult as some women may have miscarried before attendance at 
the first diabetes-antenatal clinic. Finally, we acknowledge that a randomised controlled trial would have been the ideal study design to fully determine effectiveness of the DVD. However, as initial feasibility work determined that it was not feasible to carry out a regional RCT within the primary care setting, and thus to reach as many women with diabetes as possible throughout the region, irrespective of pregnancy plans, the current study design was chosen. The authors acknowledge that a major limitation of the design is that the observed changes may have occurred for other reasons than having seen the DVD. Nonetheless, the findings of this evaluation indicate that implementation of the DVD had a positive impact on outcomes, and that viewing the DVD is associated with improved pregnancy planning indicators, regardless of process.

Despite a targeted distribution campaign, our study shows that reaching all women with diabetes, particularly those with type 2 diabetes, remains a challenge. This is in keeping with other studies where pre-pregnancy care rates were lower in women with type 2 diabetes $[16,25,27]$. In our study only $34 \%$ of GP practices actively engaged with the distribution programme, in contrast to all diabetes care teams. As GPs are often the sole providers of diabetes care in type 2 diabetes, our study highlights the urgent need for primary care to further engage in preconception counselling for women with diabetes, especially those with type 2 diabetes. A recent study reported that GPS and secondary care professionals differ in their perception of the number of women with diabetes requiring preconception care and regarding the role of GPs in that care [28]. A greater awareness of the importance of preconception counselling is needed and all healthcare professionals must avail of every opportunity to have that 'conversation' with women. A resource such as this DVD is an ideal tool to assist 
healthcare professionals in offering preconception counselling to women with diabetes. In this resource roll-out, $30 \%$ of those women who said they received the DVD did not watch it. To maximise impact and reach, and address non-engagement with the resource the Women with Diabetes project team have subsequently converted the DVD to a mobile friendly website (www.womenwithdiabtes.net) [29], which now includes an e-learning continuing professional development resource for healthcare professionals. Finally, women who viewed the DVD were also less likely to come from a deprived background, again in keeping with other studies [16,25], and further highlighting the continuing need to develop novel approaches to reach socially deprived communities.

This regional evaluation of the implementation of a preconception counselling resource for women with diabetes into routine care demonstrates improved pregnancy planning indicators post implementation.. While challenges remain to engage women, those who viewed the resource were better prepared for pregnancy in terms of glycemic control and folic acid uptake. Our findings also highlight the ongoing challenges of reaching all women with diabetes, in particular those with type 2 diabetes and those from socially deprived backgrounds. Future programmes need to consider a joint approach between primary and secondary care services to increase reach of educational resources and hence maximize benefit for all women with diabetes.

Conflicts of Interest: None of the authors have any potential conflicts of interest 
The authors present this study on behalf of a larger team, ${ }^{\star}$ The Women with Diabetes

Project Team: Core project team: Dr Valerie Holmes (Principal Investigator) and Prof Fiona Alderdice, Queen's University Belfast; Prof David McCance, Belfast Health and Social Care Trust; Prof Roy Harper, South Eastern Health and Social Care Trust, UK. Research Fellows: Dr Michelle Spence, Dr Lesley Hamill, Dr Aisling Gough, Queen's University Belfast, UK. Service Evaluation Midwives: Sarah Loughridge and Sonia McKenna, Belfast Health and Social Care Trust. Data entry: Meadhbh Hogg and Meghan Deery, Queen's University Belfast, UK. Project Statistician: Prof Chris Patterson, Queen's University Belfast, UK. DVD Development advisory group: $\mathrm{Dr}$ Michelle McKinley, Queen's University Belfast; Dr Mark Davies, Belfast Health and Social Care Trust; Dr John Manderson, South Eastern Health and Social Care Trust; Una McErlean, Belfast Health and Social Care Trust; Dr Kieran McGlade, Queen's University Belfast; Lynne Thomas, South Eastern Health and Social Care Trust, UK. Diabetes-Antenatal Clinic Leads: Prof David McCance, Belfast Health and Social Care Trust; Prof Roy Harper and Dr Ciara Mulligan, South Eastern Health and Social Care Trust; Dr Adele Kennedy, Northern Health and Social Care Trust; Dr Neil Black and Dr John Lindsay, Western Health and Social Care Trust; Dr Mae McConnell, Southern Health and Social Care Trust, UK.

\section{Acknowledgements:}

Funding Source: Diabetes UK (grant number 07/0003548).

The authors wish to thank Mr. Trevor Hartin, Vacant Square, Digital Media Production Services, Belfast, UK and Mr. Bob Price, Motion Graphic Artist, Bangor, Co. Down, UK for producing the DVD; and Mr. David Robinson and his team, Information Services, 
Queen's University Belfast, UK for website development. Finally, we wish to thank the volunteers (women with diabetes) for their involvement in the development, filming and evaluation of the DVD. Parts of this study were presented in abstract form at the Diabetes UK 2014 Professional Conference, Liverpool, UK, 5-7 March 2014 (runner up for Education Award) and the Nutrition Society Irish Section meeting, Coleraine, Northern Ireland, 18-20 June 2014.

\section{References}


[1.] CEMACH. Pregnancy in Women with Type 1 and Type 2 Diabetes in 20022003, England, Wales and Northern Ireland. London: Confidential Enquiry into Maternal and Child Health, 2005.

[2.] Jensen DM, Damm P, Moelsted-Pedersen L, Ovesen P, Westergaard JG, Moeller M, Beck-Nielsen H. Outcomes in type 1 diabetic pregnancies: a nationwide, population-based study. Diabetes Care 27 (2004) 2819-2823.

[3.] Evers IM, de Valk HW, Visser GH. Risk of complications of pregnancy in women with type 1 diabetes: nationwide prospective study in the Netherlands. BMJ 328 (2004) 915.

[4.] Hadden DR, Alexander A, McCance DR, Traub AI, Northern Ireland Diabetes Group, Ulster Obstetrical Society. Obstetric and diabetic care for pregnancy in diabetic women: 10 years outcome analysis, 1985-1995. Diabet. Med. 18 (2001) 546-553.

[5.] Sibai BM, Caritis S, Hauth J, Lindheimer M, VanDorsten JP, MacPherson C, et al. Risks of preeclampsia and adverse neonatal outcomes among women with pregestational diabetes mellitus National Institute of Child Health and Human Development Network of Maternal-Fetal Medicine Units. Am. J. Obstet. Gynecol. 182 (2000) 364-369.

[6.] Inkster ME, Fahey TP, Donnan PT, Leese GP, Mires GJ, Murphy DJ. Poor glycated haemoglobin control and adverse pregnancy outcomes in type 1 and type 2 diabetes mellitus: systematic review of observational studies. BMC Pregnancy Childbirth 6 (2006) 30.

[7.] Pearson DW, Kernaghan D, Lee R, Penney GC, Scottish Diabetes in Pregnancy Study Group. The relationship between pre-pregnancy care and 
early pregnancy loss, major congenital anomaly or perinatal death in type I diabetes mellitus. BJOG 114 (2007) 104-107.

[8.] Murphy HR, Roland JM, Skinner TC, Simmons D, Gurnell E, Morrish NJ, et al. Effectiveness of a regional prepregnancy care program in women with type 1 and type 2 diabetes: benefits beyond glycemic control. Diabetes Care 33 (2010) 2514-2520.

[9.] Ray JG, O'Brien TE, Chan WS. Preconception care and the risk of congenital anomalies in the offspring of women with diabetes mellitus: a meta-analysis. QJM 94 (2001) 435-444.

[10.] Wahabi HA, Alzeidan RA, Bawazeer GA, Alansari LA, Esmaeil SA. Preconception care for diabetic women for improving maternal and fetal outcomes: a systematic review and meta-analysis. BMC Pregnancy Childbirth $10(2010) 63$.

[11.] National Institute for Clinical Excellence (NICE) (Great Britain): Diabetes in pregnancy: Management from preconception to the postnatal period. (Available from http://www.nice.org.uk/guidance/ng3; accessed 20 Jan 2015)

[12.] American Diabetes Association: Standards of medical care in diabetes-2014. Diabetes Care 37 Suppl. 1 (2010) S14-S80

[13.] Kim C, Ferrara A, McEwen LN, Marrero DG, Gerzoff RB, Herman WH, TRIAD Study Group. Preconception care in managed care: the translating research into action for diabetes study. Am. J. Obstet. Gynecol. 192 (2005) 227-232.

[14.] Varughese GI, Chowdhury SR, Warner DP, Barton DM. Preconception care of women attending adult general diabetes clinics--are we doing enough? Diabetes. Res. Clin. Pract. 76 (2007) 142-145. 
[15.] Temple R. Preconception care for women with diabetes: is it effective and who should provide it? Best. Pract. Res. Clin. Obstet. Gynaecol. 25 (2011) 314.

[16.] Confidential Enquiry into Maternal and Child Health. Diabetes in Pregnancy: Are we providing the best care? Findings of a National Enquiry: England, Wales and Northern Ireland. London: CEMACH, 2007.

[17.] Spence M, Alderdice FA, Harper R, McCance DR, Holmes VA. An exploration of knowledge and attitudes related to pre-pregnancy care in women with diabetes. Diabet. Med. 27 (2010) 1385-1391.

[18.] McCorry NK, Hughes C, Spence D, Holmes VA, Harper R. Pregnancy planning and diabetes: a qualitative exploration of women's attitudes toward preconception care. J. Midwifery Womens Health 57 (2012) 396-402.

[19.] Spence M, Harper R, McCance DR, Alderdice F, McKinley M, Hughes C, Holmes VA. "Women with Diabetes: Things You Need to Know (But Maybe Don't!)"; the systematic development of an innovative DVD to raise awareness of preconception care. Eur. Diabetes Nursing 12 (2013) 7-12.

[20.] Holmes VA, Spence M, McCance DR, Patterson CC, Harper R, Alderdice FA. Evaluation of a DVD for women with diabetes: impact on knowledge and attitudes to preconception care. Diabet. Med. 29 (2012) 950-956.

[21.] Burns AC. The expanded health belief model as a basis for enlightened preventive health care practice and research. J Health Care Mark 12 (1992) $32-45$.

[22.] Northern Ireland Statistics Agency Multiple Deprivation Measure 2010. http://www.nisra.gov.uk/deprivation/nimdm 2010.htm. Accessed 21 Nov 2013. 
[23.] McCance DR, Holmes VA, Maresh MJ, Patterson CC, Walker JD, Pearson DW, Young IS, Diabetes and Pre-eclampsia Intervention Trial (DAPIT) Study Group. Vitamins C and E for prevention of pre-eclampsia in women with type 1 diabetes (DAPIT): a randomised placebo-controlled trial. Lancet 376 (2010) 259-266.

[24.] Willhoite MB, Bennert HW Jr, Palomaki GE, Zaremba MM, Herman WH, Williams JR, Spear NH. The impact of preconception counseling on pregnancy outcomes. The experience of the Maine Diabetes in Pregnancy Program. Diabetes Care 16 (1993) 450-455.

[25.] Tripathi A, Rankin J, Aarvold J, Chandler C, Bell R. Preconception counselling in women with diabetes: a population-based study in the north of England. Diabetes Care 33 (2010) 586-588.

[26.] Charron-Prochownik D, Ferons-Hannan M, Sereika S, Becker D.

Randomized efficacy trial of early preconception counseling for diabetic teens (READY-girls). Diabetes Care 31 (2008) 1327-1330.

[27.] Roland JM, Murphy HR, Ball V, Northcote-Wright J, Temple RC. The pregnancies of women with Type 2 diabetes: poor outcomes but opportunities for improvement. Diabet Med 22 (2005) 1774-1777.

[28.] Mortagy I, Kielmann K, Baldeweg SE, Modder J, Pierce MB. Integrating preconception care for women with diabetes into primary care: a qualitative study. Br J Gen Pract 60 (2010) 815-821.

[29.] Women with diabetes preconception counselling resource. www.womenwithdiabetes.net. Accessed 20 Jan 2016. 
Table 1. Characteristics of pregnant women with diabetes in Northern Ireland before and after the DVD launch, and of the subgroup of women who viewed the DVD prior to their pregnancy

\begin{tabular}{|c|c|c|c|c|c|}
\hline & $\begin{array}{l}\text { Pre DVD } \\
(N=114)\end{array}$ & $\begin{array}{l}\text { Post DVD } \\
(N=135)\end{array}$ & $P$ value* & $\begin{array}{l}\text { Viewed DVD } \\
(N=58)\end{array}$ & $P$ value $* *$ \\
\hline Age, yr, mean (SD) [n] & $30.9(6.5)[114]$ & $31.3(5.6)[135]$ & 0.60 & $32.0(4.7)[58]$ & 0.23 \\
\hline White ethnicity, n/N (\%) & $111 / 114(97.4)$ & $129 / 135(95.6)$ & 0.51 & $56 / 58(96.6)$ & 1.00 \\
\hline \multicolumn{6}{|l|}{ Type of Diabetes, n/N (\%) } \\
\hline Type 1 & $88(77.2)$ & $95(70.4)$ & 0.22 & $50(86.2)$ & 0.16 \\
\hline Type 2 & $26(22.8)$ & $40(29.6)$ & & $8(13.8)$ & \\
\hline \multicolumn{6}{|l|}{ Deprivation category, n/N (\%) } \\
\hline 1 (most deprived) & $31 / 114(27.2)$ & 28/134 (20.9) & $0.02^{\dagger}$ & 7/57 (12.3) & $0.001^{\dagger}$ \\
\hline 2 & 27/114 (23.7) & 23/134 (17.2) & & 9/57 (15.8) & \\
\hline 3 & 28/114 (24.6) & 31/134 (23.1) & & 15/57 (26.3) & \\
\hline 4 & 17/114 (14.9) & 29/134 (21.6) & & 12/57 (21.1) & \\
\hline 5 (least deprived) & $11 / 114(9.6)$ & 23/134 (17.2) & & $14 / 57(24.6)$ & \\
\hline Nulliparous, n/N (\%) & $52 / 114(45.6)$ & $44 / 135(32.6)$ & 0.035 & $23 / 58(39.7)$ & 0.46 \\
\hline Diabetes duration, yr, mean (SD) [n] & $12.0(8.5)[113]$ & $12.1(8.7)[135]$ & 0.94 & $15.6(8.8)[58]$ & 0.01 \\
\hline BMI at booking, $\mathrm{kg} / \mathrm{m}^{2}$, mean (SD) [n] & $28.2(5.7)[102]$ & $28.8(6.9)[133]$ & 0.44 & $26.7(5.0)[58]$ & 0.11 \\
\hline $\begin{array}{l}\text { Overweight } / O \text { bese }\left(B M I>=25 \mathrm{~kg} / \mathrm{m}^{2}\right) \text { at } \\
\text { booking, } \mathrm{n} / \mathrm{N}(\%)\end{array}$ & $65 / 102(63.7)$ & $86 / 133(64.7)$ & 0.88 & $31 / 58$ (53.4) & 0.20 \\
\hline
\end{tabular}


Table 2. Pregnancy planning indicators of women with diabetes in Northern Ireland before and after the DVD launch, and of the subgroup of women who viewed the DVD prior to their pregnancy

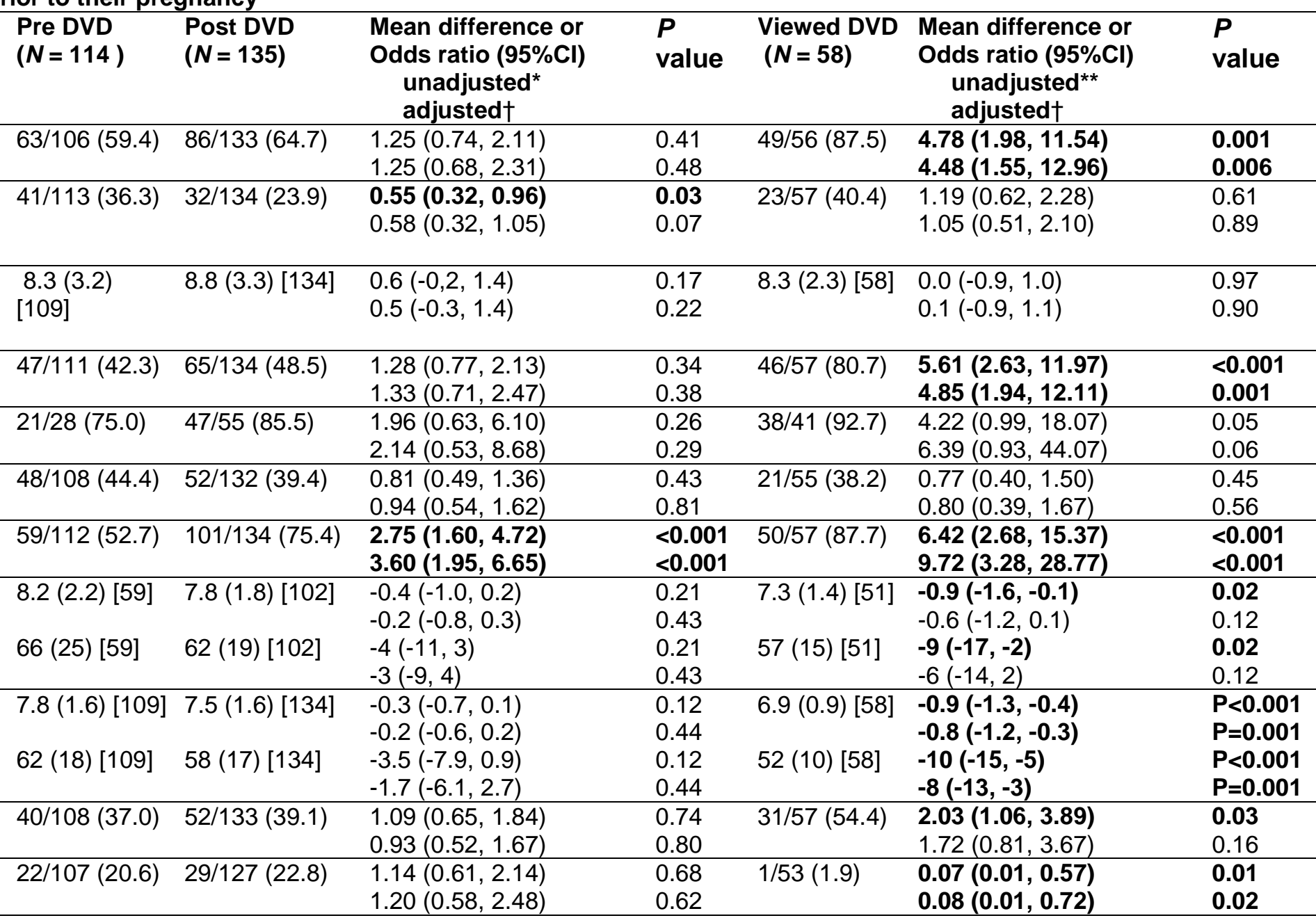

\begin{tabular}{l} 
Record in antenatal notes of \\
attending /receiving pre-pregnancy \\
counselling \\
\hline Gestational age at $1^{\text {st }}$ visit to joint
\end{tabular}

Gestational age at $1^{\text {st }}$ visit to joint

antenatal-metabolic clinic, weeks

Taking folic acid preconception

n

Taking 5mg folic acid preconception

(where dose recorded)

Documentation of contraceptive use

before pregnancy

HbA1c result recorde

prior to this pregnancy

Most recent $\mathrm{HbA1c}$ result in

prior to this pregnancy, \%

prior to this pregnancy, $\mathrm{mmol} / \mathrm{mol}$,

$\mathbf{1}^{\text {st }} \mathrm{HbA1c}$ recorded at joint diabetes-

antenatal clinic, \%

$1^{\text {st }} \mathrm{HbA1c}$ recorded at joint diabetes-

antenatal clinic, $\mathrm{mmol} / \mathrm{mol}$

HbA1c < 7.0\% (53.0 mmol/mol) at $1^{\text {st }}$

antenatal clinic

Current smoker

$1.20(0.58,2.48)$

0.62

0.02

Data are mean (standard deviation) [n] and mean difference (95\%Cl) or n/N (\%) and odds ratio (95\%Cl). *Pre DVD vs. Post DVD; *^ Pre DVD vs.

Watched DVD; Comparisons made using the Student's $t$-test for continuous variables and the chi-squared test for categorical variables. †Adjusted

for diabetes type, diabetes duration, parity, deprivation, age, and booking hospital.

Table 3. Pregnancy progress indicators and pregnancy outcomes of women with diabetes in Northern Ireland before and after the DVD launch, and of the subgroup of women who viewed the DVD prior to their pregnancy

\begin{tabular}{|c|c|c|c|c|c|c|}
\hline $\begin{array}{l}\text { Pre-DVD } \\
(N=114)\end{array}$ & $\begin{array}{l}\text { Post DVD } \\
(N=135)\end{array}$ & $\begin{array}{l}\text { Mean difference or } \\
\text { Odds ratio }(95 \% \mathrm{Cl}) \\
\text { unadjusted* } \\
\text { adiusted } \dagger\end{array}$ & $P$ value & $\begin{array}{l}\text { Viewed DVD } \\
(N=58)\end{array}$ & $\begin{array}{l}\text { Mean difference or } \\
\text { Odds ratio }(95 \% \mathrm{Cl}) \\
\text { unadjusted }{ }^{*}\end{array}$ & $P$ value \\
\hline
\end{tabular}




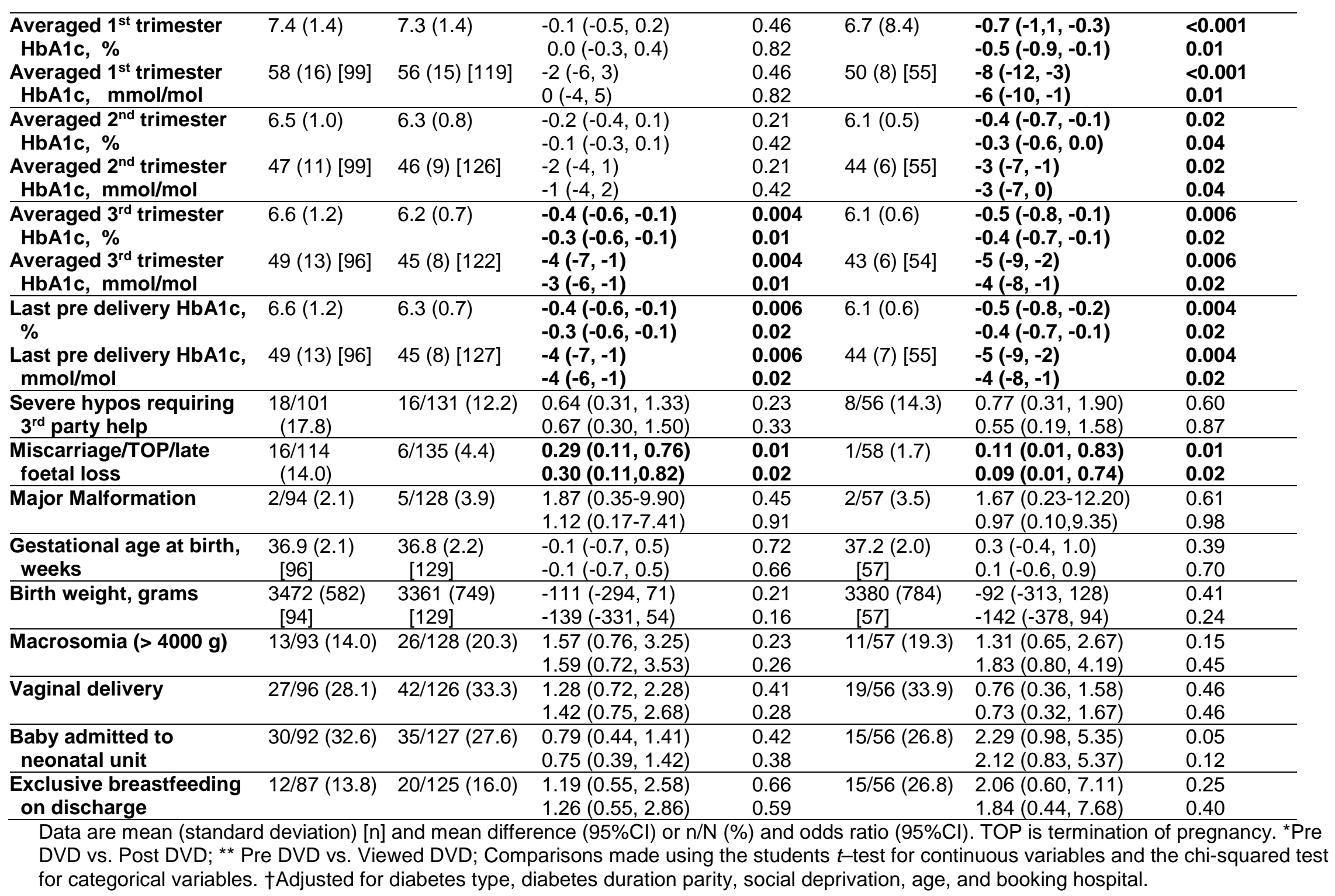


Figure 1. Flow Chart of Resource Adoption, Recruitment and Service Evaluation.

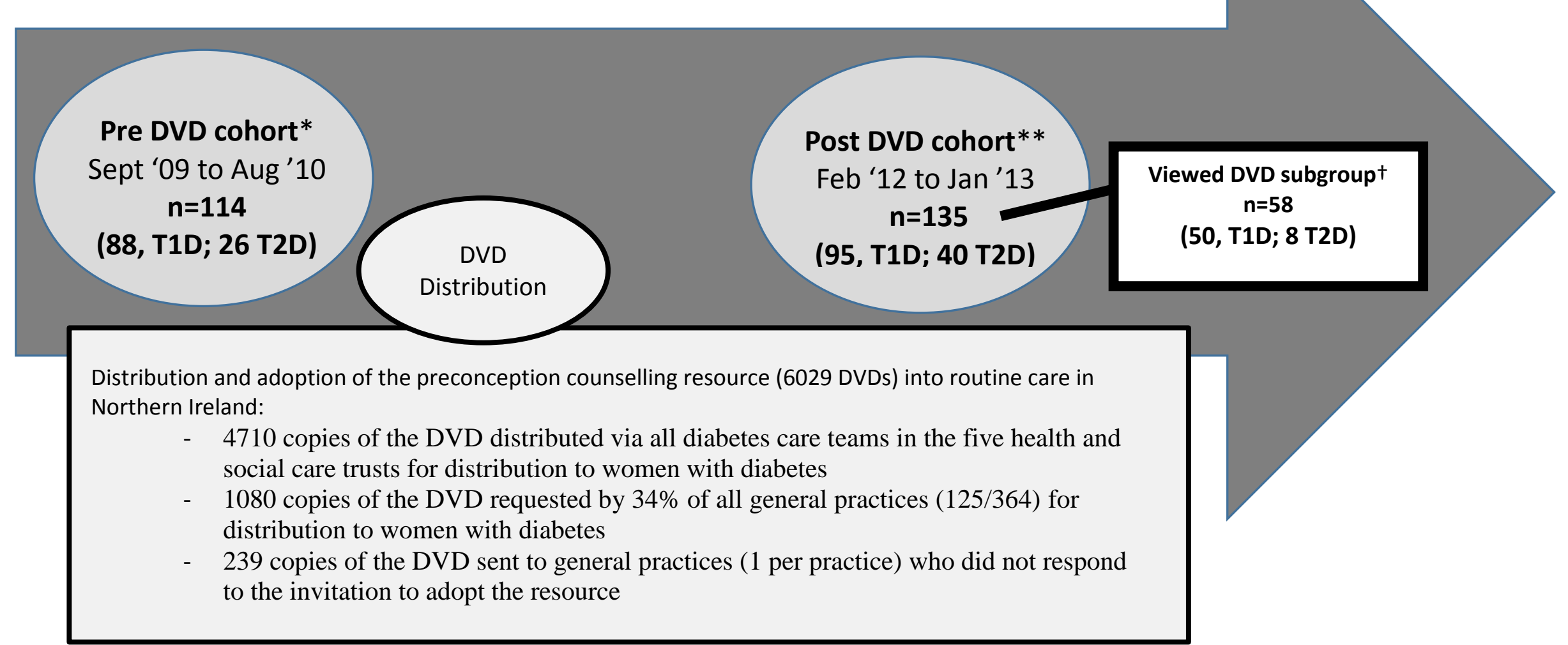

*Pre DVD cohort of women with Type 1 diabetes (T1D) and Type 2 diabetes (T2D) who delivered/expected to deliver between 01 September 2009 and 31 August 2010.

**Post DVD comparison cohort of women with T1D and T2D who delivered/expected to deliver between 01 February 2012 and 31 January 2013 $+64 \%$ of women in the Post DVD cohort reported receiving the DVD ( $n=84: 70$, T1D 14, T2D) 